\title{
ANTI-INFLAMMATORY ACTIVITY OF ROOT OF DECALEPSIS HAMILTONII
}

\author{
${ }^{*}$ Mohua Sengupta ${ }^{1}$, AK Ghosh ${ }^{2}$, Indrani Dalal ${ }^{3}$, Suhrita Paul ${ }^{4}$ \\ ${ }^{1}$ Assistant Professor, Department of Pharmacology, Medical College, Kolkata \\ ${ }^{2}$ Professor, Department of Pharmacology, Medical College, Kolkata \\ ${ }^{3}$ Assistant Professor, Department of Pharmacology, Midnapore Medical College, Kolkata \\ ${ }^{4}$ Professor, Department of Pharmacology, Medical College, Kolkata \\ *Corresponding Author: Dr. Mohua Sengupta, E Mail: senguptamohua@yahoo.co.in
}

Received 01 Dec 2012; Review Completed 04 Jan 2013; Accepted 12 Jan 2013, Available online 15 Jan 2013

\begin{abstract}
:
Powdered root of Decalepsis hamiltonii was used to evaluate the acute \& chronic anti-inflammatory activities in rodents. Albino rats of either sex were divided into 4 sets $(n=24)$. Set $A, B, C$ was used for evaluating the anti inflammatory activity after inducing acute inflammation with Carrageenan, bradykinin and 5HT respectively while Set D was used for evaluating the anti inflammatory activity after inducing chronic inflammation with formaldehyde. Each set was subdivided into four groups I-IV ( $n=6)$. In all the sets, GR I served as control (receiving gum acacia only), GR II received root extract of D. hamiltonii at the dose of $250 \mathrm{mg} / \mathrm{kg}$, GR III received Phenylbutazone $50 \mathrm{mg} / \mathrm{Kg}$, and GR IV received Dexamethasone $0.5 \mathrm{mg} / \mathrm{Kg}$. There was inflammatory inhibition of $35.55 \%$ in Carrageenan induced, $42.62 \%$ in $5 \mathrm{HT}$ induced and $36.62 \%$ in bradykinin induced acute inflammatory models. In the chronic Inflammatory model, a progressive inhibition of $36.84 \%\left(3^{\text {rd }}\right.$ day), 36.45\% (5th day), 51.45\% $\left(7^{\text {th }}\right.$ day) and $66.39 \%\left(13^{\text {th }}\right.$ day) was observed with study compound. The efficacy was comparable to the standard drugs. To summarize, we can say that Decalepsis hamiltonii is an anti-inflammatory and anti arthritic agent that may block histamine and serotonin path way. It may be an effective alternative to NSAIDs and corticosteroids in inflammatory disorders.

Key Word: Anti inflammatory activities, D. hamiltonii, rodent.
\end{abstract}

\section{INTRODUCTION:}

Decalepsis Hamiltonii (Wight\& Arn), popularly known as swallow root in English, belongs to the family Asclepiadaceae. It is a climber with stout, smooth branches shrub and a native of the forests of Deccan peninsula and Western Ghats of India. The leaves are curvaceous, orbicular or elliptical, with rounded tip. Its tubers are consumed as pickles and the juice for its alleged health promoting properties The Root has a sweet sarsaparilla-like taste; contains $9.2 \%$ fleshy matter and $8 \%$ woody core $)^{1}$. It contains quercetin, kaempferol, coumarin and rutin and considered as "Sariva Bheda" in Ayurveda where these find use as an alternative to the roots of Hemidesmus indicus in the preparation of several herbal drugs like Amrutamalaka taila (hair tonic), Drakshadi churna (general vitalizer), Shatavari rasayana (adapatogenic) and Yeshtimadhu taila (mild analgesic, anti rheumatism). The root can be stored for longer period and remains unaffected by microorganisms and insects, apparently due to the presence of a volatile principle with bacteriostatic and toxic properties which can be isolated by steam distillation. It has been extensively used as preservative and also as a source of bio insecticide in stored food grains due to the presence of strong aroma and 4-0-methyl resorcylaldehyde (0.9-12\%.). ${ }^{2}$

Although the roots of $D$. hamiltonii have been used for their alleged health benefits, scientific investigation in this regard need to be done. Though many researchers establish the anti oxidant, anti bacterial and anti ulcerogenic role of the root extract of $\mathrm{D}$. hamiltonii, very few have explored the anti inflammatory potential. The anti-inflammatory drugs (NSAIDs) presently available are not free of side effects like gastric ulceration, kidney damage etc so an alternative drug obtained from natural sources devoid of side effects would be useful in treatment of acute and chronic inflammatory diseases. The aim of the present study was therefore to evaluate the acute $\&$ chronic anti-inflammatory activities of the extract of root of Decalepsis Hamiltonii in rodents.

\section{MATERIALS \& METHOD:}

\section{Animals}

Albino rats of either sex weighing between 150-200 grams were used for this experiment. The rats were kept in polysulfone rat cages and maintained at a $12 \mathrm{~h}$ light / dark cycle. The temperature was maintained at $22-26^{\circ} \mathrm{C}$ while the relative humidity was $50-60 \%$. The experiment was conducted in the Department of Pharmacology, Medical College Kolkata in collaboration with West Bengal University of Animal and Fishery Sciences, Mohanpur Campus. Rats were fed on standard pellet diet and provided filtered autoclaved ad libitum drinking water. The experiments were performed following approval by the Institutional Animal Ethics Committee of WBUAFS.

\section{Plant Extract}

Powdered root of Decalepsis Hamiltonii (5 $\mathrm{Kg}$ ) was obtained from the Chemical Research and Extraction. Supply Unit of CCRAS and extracted with petrol ether $\left(60^{\circ}-80^{\circ} \mathrm{C}\right)$ in sox let apparatus for 15 hours and solvent was removed by distillation. The residual gummy material obtained was then suspended in 5\% gum acacia and used for oral administration to the experimental animals at a dose of $250 \mathrm{mg} / \mathrm{kg}$ body wt after standardizing according to their LD 50 \& ED 50 determined before selecting the dose. 
Carrageenan (sigma), 5HT (Roche Pharmaceuticals), Bradykinin (BRA 640, San Doz), Formaldehyde, Phenylbutazone (SG Pharmaceuticals), Dexamethasone (MSD), Gum acacia.

\section{Procedure:}

As the indigenous drug was insoluble in water it was suspended in 5\% gum acacia solution. The rats were divided in five groups $(n=6)$ and the drugs were given orally with the help of rat feeding canula fitted to $2 \mathrm{ml}$ glass syringe keeping the volume of medicament constant (1ml) one hour prior to Carrageenan injection (for inducing inflammation).

GR I served as control (receiving gum acacia only)

GR II received root extract of D. hamiltonii, $250 \mathrm{mg} / \mathrm{kg}$

GR III received root extract of D. hamiltonii, $500 \mathrm{mg} / \mathrm{kg}$

GR IV received Phenylbutazone $50 \mathrm{mg} / \mathrm{Kg}$

GRV received Dexamethasone $0.5 \mathrm{mg} / \mathrm{Kg}$

The average volume of hind paw of all the rats was measured with the help of a plethismograph by the method of Buttle et $\mathrm{al}^{3}$ after some modification and noted before inducing acute inflammation with Carrageenan.

\section{Paw edema induced to produce acute inflammation:}

Carrageenan, 5HT and bradykinin induced edema was adopted as introduced by Winter, Risley and Nuss ${ }^{4}$ with slight modification by Ghosh \& Singh. ${ }^{5}$ Carrageenan $1 \%$ in $0.9 \% \mathrm{w} / \mathrm{v}$ Sodium Chloride was taken and $0.1 \mathrm{ml}$ of such solution was injected in sub planter region of hind paw of all the rats one hour after the administration of the drugs. The paw volume was again measured twice after 1 hour and at the end of 3 hours and noted. Increase in volume of paw edema was recorded by subtracting the initial paw volume from final paw volume measured with the help of Plethysmograph after 1 hour and 3 hours of Carrageenan injection.

Percentage of inhibition of inflammation rate was calculated as

Vc-Vt
Vc

Where

Table-I: Effects of Decalepsis hamiltonii, Phenylbutazone and Dexamethasone on carrageenan induced edema of rat hind paw $(\mathbf{n}=6)$

\begin{tabular}{|c|c|c|c|}
\hline Group & Mean increase in paw volume (in ml \pm SE) & \% inhibition & P Value \\
\hline GR I & $0.9 \pm 0.10$ & - & - \\
\hline GR II & $0.58 \pm 0.06$ & 35.55 & $\mathrm{P}<.05$ \\
\hline GR III & $0.43 \pm 0.11$ & & \\
\hline GR IV & $0.23 \pm 0.02$ & 74.44 & $\mathrm{P}<.001$ \\
\hline GR V & $0.3 \pm 0.03$ & 66.66 & $\mathrm{P}<.01$ \\
\hline
\end{tabular}


Table-II: Effects of Decalepsis hamiltonii, Phenylbutazone and Dexamethasone on 5HT induced paw edema of rat hind paw ( $n=6)$

\begin{tabular}{|c|c|c|c|}
\hline Group & Mean increase in paw volume (in ml \pm SE) & \% inhibition & P Value \\
\hline GR I & $0.61 \pm 0.04$ & - & - \\
\hline GR II & $0.35 \pm 0.05$ & 42.62 & $\mathrm{P}<.01$ \\
\hline GR III & $0.18 \pm 0.03$ & 70.49 & $\mathrm{P}<.001$ \\
\hline GR IV & $0.3 \pm 0.03$ & 50.81 & $\mathrm{P}<.001$ \\
\hline
\end{tabular}

Table-III: Effects of Decalepsis hamiltonii, Phenylbutazone and Dexamethasone onBradykinin induced paw edema of rat hind paw $(n=6)$

\begin{tabular}{|c|c|c|c|}
\hline Group & Mean increase in paw volume (in ml \pm SE) & \% inhibition & P Value \\
\hline GR I & $0.71 \pm 03$ & - & - \\
\hline GR II & $0.45 \pm 0.04$ & 36.62 & $\mathrm{P}<.01$ \\
\hline GR III & $0.22 \pm 0.4$ & 69.01 & $\mathrm{P}<.001$ \\
\hline GR IV & $0.32 \pm 0.03$ & 54.92 & $\mathrm{P}<.001$ \\
\hline
\end{tabular}

TABLE - IV: Effects of Decalepsis hamiltonii, Phenylbutazone and Dexamethasone on Formaldehyde induced paw edema in rats $(n=6)$

\begin{tabular}{|c|c|c|c|c|c|c|}
\hline Group & \multicolumn{6}{|c|}{ Mean increase in Paw Volume (ml \pm SE) } \\
\hline & $\mathbf{3}^{\text {rd }}$ Day & $\mathbf{5}^{\text {th }}$ Day & $\mathbf{7}^{\text {th }}$ Day & $\mathbf{9}^{\text {th }}$ Day & $\mathbf{1 1}^{\text {th }}$ Day & $\mathbf{1 3}^{\text {th }} \mathbf{D a y}^{-1.03}$ \\
\hline GR I & $0.95 \pm 0.02$ & $0.96 \pm 0.02$ & $1.03 \pm 0.05$ & $1.16 \pm 0.12$ & $1.23 \pm 0.13$ & $1.13 \pm 0.09$ \\
\hline GR II & $0.71 \pm 0.03$ & $0.66 \pm 0.04$ & $0.63 \pm 0.04$ & $0.6 \pm 0.03$ & $0.55 \pm 0.03$ & $0.5 \pm 0.05$ \\
& $25.26 \%$ & $31.25 \%$ & $38.83 \%$ & $48.27 \%$ & $55.28 \%$ & $55.75 \%$ \\
& $\mathrm{P}<.001$ & $\mathrm{P}<.001$ & $\mathrm{P}<.001$ & $\mathrm{P}<.01$ & $\mathrm{P}<.01$ & $\mathrm{P}<.001$ \\
\hline GR III & $0.7 \pm 0.03$ & $0.65 \pm 0.02$ & $0.62 \pm 0.04$ & $0.58 \pm 0.03$ & $0.5 \pm 0.04$ & $0.4 \pm 0.04$ \\
& $26.32 \%$ & $32.29 \%$ & $39.80 \%$ & $59 \%$ & $59.34 \%$ & $64.60 \%$ \\
& $\mathrm{P}<.001$ & $\mathrm{P}<.001$ & $\mathrm{P}<.001$ & $\mathrm{P}<.01$ & $\mathrm{P}<.01$ & $\mathrm{P}<.001$ \\
\hline GRIV & $0.60 \pm 0.6$ & $0.61 \pm 0.06$ & $0.50 \pm 0.06$ & $0.46 \pm 0.04$ & $0.43 \pm 0.04$ & $0.38 \pm 0.03$ \\
& $36.84 \%$ & $36.45 \%$ & $51.45 \%$ & $60.34 \%$ & $65.50 \%$ & $66.39 \%$ \\
& $\mathrm{P}<.01$ & $\mathrm{P}<.01$ & $\mathrm{P}<.001$ & $\mathrm{P}<.01$ & $\mathrm{P}<.01$ & $\mathrm{P}<.001$ \\
\hline
\end{tabular}

\section{DISCUSSION:}

Medicinal plants are nature's hidden and to a large extent unexplored treasure. They have been used as a source of safe and effective medicine since time immemorial, as they are less toxic, cheap and suitable for use over a prolonged period. This potential resource has hardly been commercially tapped. India is endowed with about 8000 species of medicinal plants. According to a recent estimate of the Planning Commission, Government of India, the potential for plant-based crude drugs is about Rs. 400 billion. Globally, the demand for medicinal plants and their derivatives is growing at a rate of $7-15 \%$. Only a few medicinal plants have been selected for scientific testing and experimentation as inflammatory agents. Moreover, the active principles responsible for the alleged health promoting activity need to be isolated to elucidate their exact mode of action.

Chopra $^{6}$ pioneered the usefulness of indigenous drugs various diseases including arthritic conditions. Earlier works have shown that the $D$. hamiltonii roots contain aldelydes, amyrins, lupeols and volatile flavour compounds such as 2-hydroxy-4methoxybenzaldehyde, vanillin etc and essential oil like 4methylresorcylaldehyde, atlantone, terpinene, geraniol etc. A combinational molecule containing pectic polysaccharide with bound phenolics identified in the root of D. hamiltonii and their break down products have been known to have health beneficial properties. ${ }^{7}$. This highly aromatic root has been subjected to over exploitation by destructive harvesting that has endangered the survival of this plant. A method for rooting of D. hamiltonii for field transfer is reported ${ }^{8}$.

Flavonoids and occasionally polysaccharides present in various plant products have frequently been implicated as antioxidant and antiulcer agents ${ }^{9}$. Various workers have proved the antibacterial activity supercritical extract of swallow root ${ }^{10}$. Some claim that it is gastro protective in nature and possibly inhibits the $\mathrm{H}^{+} \mathrm{K}^{+}$ATPase enzyme responsible for $\mathrm{HCl}$ secretion in stomach. ${ }^{11}$ while some state that it has multistep ulcer protective activity, ${ }^{12}$ and antioxidative properties ${ }^{13}$. The inhibition of carageenaninduced inflammation in rats is an established model to screen compounds for potential anti-inflammatory activity. According to Vinegar et al $^{\mathbf{1 4}}$ the development of carrageen induced edema is biphasic; the first phase occurs within one hour of carageenan administration and attributed to the release of cytoplasmic enzymes, histamine and serotonin, from the mast cells. The second phase $(>1.0 \mathrm{~h})$ is mediated by an increased release of prostaglandins in inflammatory area and continuity between the two phases is maintained by kinins. Taken together, it suggests root of $\mathrm{D}$ hamiltonii possesses potent anti-inflammatory activity (Table I-III) possibly due to inhibition and/or release of inflammatory mediators, principally the prostaglandins. Anti inflammatory effect is also seen in inflammation produced 
Sengupta et al

Journal of Drug Delivery \& Therapeutics; 2013, 3(1), 70-73

by $5 \mathrm{HT}$ and Bradykinin, that proves it may have some action by inhibiting the pain pathway that caused by $5 \mathrm{HT}$ and Bradykinin.

Formaldehyde induced arthritis is generally used to study the efficacy of a drug against the proliferative phase of inflammation i.e. chronic inflammation. There was significant inhibition of formaldehyde induced paw edema by Decalepsis hamiltonii with the increase of number of days which suggests that it would be beneficial in treatment of arthritis and related disorders. Results of the present study corroborate with Lakshman et $a l^{15}$ who examined the effectiveness of the methanol extract of roots of Decalepis hamiltonii at 250 and $500 \mathrm{mg} / \mathrm{kg}$ doses orally in the carrageenan-induced rat paw edema and cotton pellet-induced chronic inflammatory models. The extract showed significant dose-dependent anti-inflammatory activities in both models.

Though efficacy of phenylbutazone was the most in acute inflammatory model and dexamethasone was most efficacious in chronic inflammation, study compound exhibited a comparable result in both the models.

\section{REFERENCE}

1. Nagarajan,S, Jagan Mohan Rao, L and Gurudutt, K.N. Chemical composition of the volatiles of Decalepsis Hamiltonii.(Wight and Arn). Flavour and Fragrances Journal,2001;16(1)27-29.

2. George J, Pereira J, Divakar S, Udaysankar K and Ravishankar GA. A method for the preparation of active fraction from the root of Decalepis hamiltonii, useful as bioinsecticide, 1998; 1301: 98.

3. Buttle G.A.H, D. Archy PF, Howard EM and Kellet DN. Plethysmometric Measurement of Swelling in the Feet of Small Laboratory Animals Nature, London, 1957: 179: 629.

4. Winter CA, Risley EA, Nuss GW. Carrageen -induced edema in hind paws of rat as an assay for anti-inflammatory drugs. Proc Soc Expt Biol Med, 1962 ; 111: 544-47.

5. Ghosh MN and Singh,Inhibitory effect of a pyrrolidine alkaloid, crotalaburine, on rat paw oedema and cotton pellet granuloma. Brit J Pharm. 1974; 51(4): 503.

6. Chopra RN, Chopra IC, Handa KK and Kapur LD In Indigenous Drugs in India (1958); Ind. Ed.,M/S. U.N. Dhar and Sons Ltd., Calcutta.

7. James, DJ. Seaweed extracts as biostimulants of plant growth and development ,Journal of Physiol. Plant, 1983; 57: 149-153.

8. B. Obul Reddy, P Girindhar, G. Ravishankar In vitro rooting of Decalepsis hamiltonii, Wright \& Earn, Research communications, current science, 2001; 81 (11): 1140.

9. C.Proestos,I.S. Boziaris, G-J.E Nyches,M. Kamaitis. Analysis of flavonoids and phenolic acids in Greek aromatic plants: Investigation of their antioxidant capacity and antimicrobial activity.Food Chemistry.2006;95 (4):664-671.
Though NSAIDs are most commonly used in the treatment of acute and chronic inflammation, prolonged use has been limited as approximately $25 \%$ of NSAID users develop G.I symptoms ${ }^{16}$. The advent of this herbal medicine with antibacterial, anti oxidative anti-inflammatory and gastro protective action together therefore would be unique and highly beneficial to patients of acute inflammation and particularly chronic inflammatory disorders. It would be judicious to identify the specific active principles responsible for this anti inflammatory activity which would enhance the efficacy of this herbal preparation. Further studies in this regard in higher animals are recommended for positive outcome.

\section{ACKNOWLEDGEMENT:}

I want to thank all the members of department of Pharmacology, Medical College, Kolkata for their constant support to carry out my experiment.

\section{Conflict of Interest: Nil.}

10. George J, Pereira J, Divakar S, Udaysankar K and Ravishankar.In vitro propagation of Decalepsis Hamiltonii.wigh \& Arn., an endangered shrub, through axillary bud cultures. .Curr. Sci. 1999;77: 501-502.

11. Yogender Naik, Smitha Jayaram, M.A. Harish Nayaka, Lakshman and Shylaja M. Dharmesh Gastroprotective effect of swallow root (Decalepis hamiltonii) extract: Possible involvement of $\mathrm{H}^{+}-\mathrm{K}^{+}$-ATPase inhibition and antioxidative mechanism $\mathrm{J}$ Ethnopharmacology, 2007 ;112 (1): 73-79.

12.Srikanta BM, Siddaraju MN, Dharmesh SM A novel phenolbound pectic polysaccharide from Decalepis hamiltonii with multistep ulcer preventive activity. World J Gastroenterol. 2007; 13 (39): 5196-207

13. De Klerk, V. Krieken W and de Jong JC.In Vitro Cell Dev.J Biol. Plant, (1999); 35:1899.

14. Vinegar R, Traux JF, Selph JH, Johnston PR, Venable AL, Mckenzie KK. Pathway to carrageenan-induced inflammation in the hind limb of the rat. Fed Proc, (1987) ; 46: 118-26.

15. Lakshman K, Yoganarasimhan SN, Shivaprasad HN, Jaiprakash B, Mohan S Anti-inflammatory and Antipyretic Activity of Decalepis hamiltonii root extract. Pharmaceutical Biology, 2006; 44:( 2) 127-9

16. Larka EN, Smith JL, Lidsky MD, Sessons SI, Graham DY. Dyspepsia in NSAID users, The size of the problem, J Clin, Gastroenterol, 1988 ; 11:158-62 